\title{
Implementing the ACRL Framework: Reflections from the Field
}

\author{
Don Latham, Melissa Gross, and Heidi Julien
}

In an exploratory study, interviews were conducted with fifteen librarians to learn about their perceptions of and experiences with the Framework for Information Literacy for Higher Education. Participants reported that they are implementing the Framework implicitly rather than explicitly, and their instruction has become more interactive and hands-on. A key strategy to success has been getting buy-in from other librarians and faculty. The participants have encountered a number of challenges in implementing the Framework, including time constraints within the one-shot model of instruction and resistance from some librarians and faculty who feel that the Framework is too highly conceptual to be practical for students, many of whom lack basic information literacy skills. Finally, participants indicated it is difficult to assess learning based on the Framework.

\section{Introduction}

After several years of development, the Framework for Information Literacy for Higher Education was officially adopted by the Association of College and Research Libraries (ACRL) in January 2016. As stated in the introduction to the document, the Framework represents a radical departure from the skills-based approach of the Information Literacy Competency Standards for Higher Education: "The Framework ... is called a framework intentionally because it is based on a cluster of interconnected core concepts, with flexible options for implementation, rather than on a set of standards or learning outcomes, or any prescriptive enumeration of skills." ${ }^{1}$ The Framework is made up of six frames, each of which is anchored by a key information literacy concept:

- Authority Is Constructed and Contextual

- Information Creation as a Process

- Information Has Value

- Research as Inquiry

- Scholarship as Conversation

- Searching as Strategic Exploration ${ }^{2}$

Also associated with each frame are knowledge practices, "demonstrations of ways in which learners can increase their understanding of these information literacy concepts," and dispositions, "ways in which to address the affective, attitudinal, or valuing dimension of learning." ${ }^{3}$ The

\footnotetext{
* Don Latham is Professor in the School of Information and Melissa Gross is Professor in the School of Information at Florida State University; email: dlatham@fsu.edu, mgross@fsu.edu. Heidi Julien is Professor and Chair in the Department of Information Science at the University at Buffalo; email: heidijul@buffalo.edu. (C2019 Don Latham, Melissa Gross, and Heidi Julien.
} 
Framework is intended to be conceptual rather than prescriptive; as such, it allows librarians a great deal of latitude in terms of developing instructional strategies and learning assessments.

The Framework has been greeted with much excitement but also some consternation. The flexibility offered by the Framework can be a good thing, of course, offering librarians the freedom to reimagine information literacy instruction in an almost limitless variety of ways. But it can be daunting as well, leaving librarians feeling somewhat rudderless amid this sea change in how information literacy is conceptualized. Given that the Framework is still relatively new (and "novel"), now is an opportune time to investigate librarians' perceptions of the Framework and experiences with implementing it. In other words, how is the Framework being implemented in the field, and what are the results so far?

\section{Literature Review}

This study is relevant because academic librarians continue to have significant roles in information literacy instruction, ${ }^{4}$ so future librarians must be prepared to fulfill that role, in part by understanding the practices of information literacy instructors. There have been multiple analyses of instructional practices as well as of the preparation of librarians for instruction, with a strong focus on opportunities for improving both preparation and practice. ${ }^{5}$ Understanding instructional practices in today's academic libraries must begin with the foundational document intended to structure those practices, the Framework for Information Literacy for Higher Education. ${ }^{6}$

The current study builds on a small but growing literature focused on implementation of the Framework. Following the introduction of the Framework, ${ }^{7}$ the published literature focused on initial reactions, both supportive ${ }^{8}$ and critical. ${ }^{9}$ Now the literature increasingly includes case studies and reports from librarians who have attempted to implement the Framework. Many articles and books published in the last two years provide advice about how to incorporate the Framework into practice and describe successful cases. For example, Julia Bauder and Catherine Rod provide many examples of libraries that were already incorporating the threshold concepts into their information literacy instruction prior to the publication of the Framework. ${ }^{10}$

Mahrya Carncross offers a practical example of translating instructional objectives developed under the previous Standards into revised objectives that are more consistent with the Framework. ${ }^{11}$ Allison Hosier shows how one of the frames, Scholarship as Conversation, was translated into learning outcomes in an information literacy lesson. ${ }^{12}$ Trudi Jacobson and Craig Gibson provide a range of very practical strategies to implement the Framework. ${ }^{13}$ Rachel Elizabeth Scott describes how she was able to incorporate the Framework, even within the limitations of a short instructional session. ${ }^{14}$

Zoe Fisher used the Framework successfully as the basis for a credit-bearing information literacy course, and she suggests that librarians could actually ask students to read the Framework. ${ }^{15}$ She indicates that using the Framework helped her students to think more deeply about course material and to ground discussions about theory and practice. Scott demonstrates that undergraduates are capable of understanding the threshold concepts. ${ }^{16}$

Troy Swanson describes intense discussions on his campus about the threshold concepts in

the Framework, to introduce faculty to these ideas and generate commitment to implementing the Framework. ${ }^{17}$ Meredith Farkas writes that the Framework "has enriched my own teaching as I've made incremental changes toward instructional improvement and better facilitating student learning." 18 
Gloria Willson and Katelyn Angell report an attempt to map the Framework concepts onto an assessment rubric for professional standards in nursing; despite some challenges, they believe that this approach holds promise for that field. ${ }^{19}$ Sonnet Ireland argues for the value of the Framework in the public library context, specifically as a conceptual basis for educating patrons about fake news. ${ }^{20}$ Kathy Shields and Christine Cugliari write about applying the Scholarship as Conversation frame to an information literacy instructional experience for students in nonprofit studies, noting that close dialogue with faculty is critical for success. ${ }^{21}$

Others are more cautious. For example, Carrie Ludovico suggests that, for adult learners, the Framework's threshold concepts may be less transformative than informative. ${ }^{22}$ In addition, Amanda Meeks, Larissa Garcia, Ashley Peterson, and Alyssa Vincent reported an attempt to apply the Framework in the discipline of Studio Arts, with mixed success. ${ }^{23}$ Susan Franzen and Colleen Bannon argue that the Standards remain useful to bridge the Framework and evidencebased practice in health sciences, illustrating this with a curriculum map that achieves that goal. ${ }^{24}$

The experience and advice offered by the existing literature informed the research questions for the current study. In addition, despite the burgeoning literature describing how the Framework is being implemented, there is still much to learn about how academic librarians are incorporating the Framework into instruction, the efficacy of the Framework for information literacy instruction and learning outcomes, and how LIS educators can best incorporate the Framework into the professional preparation of academic librarians.

A 2016 survey administered to academic librarians in the United States gathered data about current information literacy programs, pedagogical strategies, and instructional challenges. ${ }^{25}$ The survey was distributed online via the ILI-L listserv, and 622 librarians with instructional responsibilities in an academic library context participated. Among the findings, respondents indicated that information skills instruction is only partly informed by the Framework, and 41 percent reported that the Framework has had no, or only minor, influence on their practice. Thirty-one percent indicated that the Framework has had significant influence on their practice. Some respondents reported now including topics such as social media, open access publishing, images and fair use, and citation metrics in their instruction, and the vast majority of respondents see connections between the concepts presented in the Framework and their responsibility to raise the level of information literacy among students. However, most instruction remains skills-based and, though increasingly integrating information technology, has yet to incorporate the threshold concepts articulated in the Framework.

The survey data provided a snapshot of current information literacy practices in higher education in the United States, but the data also raised additional questions. The exploratory study described here sought to address those questions in an deeper way.

\section{Research Questions}

In exploring academic librarians' perceptions of and experiences with the Framework, this study sought to address the following research questions:

1. What pedagogical strategies are being used by academic librarians in implementing the ACRL Framework?

2. What do academic librarians perceive to be the most successful strategies for implementation of the ACRL Framework?

3. What do academic librarians perceive to be the greatest challenges in implementing the ACRL Framework? 
4. How are academic librarians approaching the evaluation of student learning when implementing the ACRL Framework?

\section{Method}

To address these research questions, interview participants were recruited via the ILI-L listserv, an American Library Association listserv devoted to the topic of information literacy instruction. Ethics approval for the study was given by Florida State University. The announcement to the ILI-L listserv was posted twice during a two-week period. The message stated that participants would be entered into a drawing to win one of five $\$ 50$ gift cards. All respondents who expressed interest were allowed to participate in the study. Since this was an exploratory study, statistical significance was not the goal. Ultimately, 15 academic librarians participated in semistructured interviews conducted via Skype. The interviews were recorded and transcribed; they ranged in length from 25 minutes to 60 minutes, with the average length being 50 minutes. The interviews included some basic demographic questions and then focused on whether and how librarians were implementing the Framework in their information literacy instruction, successes in using the Framework, challenges encountered, strategies for assessing student learning, and the extent to which they felt the Framework was supplanting skills-based instruction. The interview guide is provided in the appendix.

Two of the interview transcriptions were coded independently by two of the researchers and then compared for consistency. Seven of the remaining interviews were then coded by one researcher; the other six, by the other researcher. The interviews were initially coded by hand, and then the coding was loaded into HyperResearch, a qualitative analysis software program from Researchware, Inc. A combination of preset and open codes was used. The preset codes were derived primarily from key terms in the six threshold concepts of the Framework and in the interview questions. Open codes were developed from other things participants spoke about. For example, a number of participants mentioned collaboration-with other librarians and/or with faculty. The third researcher then compared the coding from the other two researchers and confirmed that the coding was consistent.

\section{Results}

The 15 interviewees represented a variety of institutions in terms of both type and size. Three were from community colleges, three from four-year colleges, and nine from universities. One was from an institution with fewer than 100 students, four were from institutions with between 2,500 and 4,400 students, six were from institutions with between 8,000 and 20,000 students, and four were from institutions with between 21,000 and 46,000 students. Both public and private institutions were represented among the interviewees. The interviewees had a wide range of experience working in libraries, anywhere from one to 25 years, with the mean being 10.2 years and the median being 9 . There was also a variety of types of information literacy instruction offered across these libraries, with several offering more than one type. The one-shot workshop was offered by all of the libraries represented $(n=15)$. Other types of instruction included embedded librarians $(n=5)$, credit courses $(n=3)$, multiple sessions with individual classes $(n=2)$, online tutorials $(n=1)$, and an hour-long orientation $(\mathrm{n}=1)$. 


\section{RQ1: Pedagogical Strategies}

A number of the interviewees stated that the Framework is providing a structure and a guiding ideology for teaching information literacy. While the terminology of the frames is being used selectively in instruction, all six frames were mentioned in the interviews. Information Creation as a Process $(n=7)$ and Scholarship as Conversation $(n=7)$ were mentioned by about half of the interviewees. Authority Is Constructed and Contextual ( $n=5)$, Information Has Value $(n=5)$, and Searching as Strategic Exploration $(n=5)$ were mentioned by a third. Research as Inquiry $(n=4)$ was mentioned by less than a third of participants.

Rather than making explicit use of the terminology from the frames, most of the librarians are using the frames as a subtext for teaching while still providing primarily skills-based instruction. For example, Elizabeth stated:

I will mention to students the idea that scholarship is a conversation. And I will sort of specifically emphasize that when I'm explaining to them things like how they can track citations and how to look up what has cited the article that they're looking at so they can see how conversations develop over time and how that's part of the knowledge creation-process and the discipline that they're engaged in. ${ }^{26}$

Several interviewees reported that trying to implement the Framework in instruction has made their teaching more conversational (rather than strictly lecture based) and more interactive. By the same token, many of them stated that student learning involved more hands-on activities, more peer-to-peer teaching, and more group work. Holly explained the transformation in this way:

We have really tried to make our instruction much more interactive and hands-on. I think that - and this varies depending on different people in the department-but some of our instruction in the past had been this old-fashioned librarian instruction, "Here's a database. Here's how it works," that kind of thing. And I think that we're doing a lot more interactive that allows the students to engage with the texts, and it allows them to engage with each other a lot more. ${ }^{27}$

Some interviewees reported using "flipped" classrooms, in which information literacy instruction is provided online, outside the physical classroom, and then classroom time is used for having students engage in activities that allow them to gain practice in various information literacy strategies. Claire described this approach as a revelation:

I started to think a bit more about what I didn't think needed to be taught in the class anymore and how we could move some of those things that seemed a bit more process oriented to online instruction. Trying to-I knew I wasn't gonna change the one shot model that we had here right away, but I was trying to augment it in any of the interactions that I had. So, [I asked] the faculty members that I was working with to have the students do some of the-what I saw as more point here click there kind of learning. Downloading that to either before or after, so that when we did meet for the 75 minutes, we could really go into a little more depth and talk more about authority. ${ }^{28}$ 


\section{RQ2: Most Successful Strategies}

The interviewees identified several successful strategies they had used in implementing the Framework. Two of these strategies focused on preparing for implementation, both within the library and across campus. Having conversations with other librarians for the purpose of achieving buy-in was noted as being an important precursor to trying to develop any strategies for implementation. As a follow-up to these conversations, providing training in the Framework to other librarians was seen as a key implementation strategy. Likewise, the interviewees commented on the importance of introducing the Framework to faculty across campus, getting buy-in from them, and providing training to them. Alexis reported that the Framework had facilitated productive conversations with colleagues, both within the library and across campus:

I can say that probably the most successful thing that I've done with the Framework has been speaking to other librarians about teaching. And to people outside of the library. I feel like the Framework has given me the ability to demystify what the role of a librarian is outside of books. So, when I'm teaching for someone who is a hard sell, for example. Someone who has never used the library before, they don't know quite what I do, and I get a session with them describing what I'm trying to do in that session, using the Framework has a lot more value to that instructor than when I'm using the Standards. And then talking to other librarians about what I'm trying to do in the classroom using the Framework versus the Standards, it's meatier. We have better conversations about teaching and how to teach. ${ }^{29}$

Several reported that faculty reactions had generally been positive, which they attributed to the fact that some faculty found the conceptual nature of the Framework more appealing, at least intellectually, than the more skills-based approach of the Information Literacy Competency Standards.

In terms of implementing the Framework with students, several interviewees mentioned using the frames to develop learning outcomes for information literacy instruction. In addition, they noted that it is important not to try to teach all of the frames in one session, but instead to implement the frames over time. They felt that focusing on the frame(s) most relevant to a particular session, for example, in relation to a specific course assignment, is an especially effective strategy. Joanne explained how this works in her library:

We picked out the three [frames] that really aligned with the session that we were doing. Searching as Exploration, the frame regarding authority, and ... Scholarship as Conversation, yes. So, those were the three that we tried to pull out and the three that-in preparing for the academic year, we had a session with all the teaching librarians, referred to the Framework again, I tried sending them a lot of the articles that ACRL was sending out, I alerted them to the toolbox, or the toolkit, and so, I think some of them are right there with me, but certainly there's still a little bit more buy-in to get. ${ }^{30}$

\section{RQ3: Greatest Challenges}

When asked about challenges they had encountered in implementing the Framework, the interviewees identified a number of issues. Time is a major problem. Faculty do not feel that 
they can allot much time to information literacy instruction even though they may feel their students need it. As Jill explained,

The success of the Framework for student learning is just really based on faculty allowance, like what you can do in the classroom and how much time they give you. So, if you're getting your 30 minutes or even less than that, then it's really hard to dig deeper and have more high-level critical thinking things in there. ${ }^{31}$

Susan described the problem this way: "I only can basically provide one shots in my face-to-face [so] it is hard for me to develop scaffolding." 32 In addition, the librarians have found that a great deal of time and effort are required on their part to prepare for instructional sessions using the frames and to develop and implement assessment of learning outcomes. And previous information literacy instruction documentation must now be updated, which also requires a big investment of time and energy.

One reason that developing instruction is so time consuming, according to the interviewees, is that the concepts are vague and hard to teach. As Holly explained:

The Standards were much more concrete and, sometimes, when talking to faculty, it's easier to talk about things that are more concrete which is, in some ways, why we translated part of it to more specific outcomes for them and I think that that depends on, potentially, the specific faculty you're talking to. Different people have different ways of approaching these things. Some people are more comfortable with nebulous concepts and other people really want to see exactly what an outcome is going to be and we have to translate it to that. ${ }^{33}$

They are finding that it is equally difficult to assess student learning. Many of the interviewees are also concerned about whether information literacy instruction based on the frames will be scalable to multiple sessions for different disciplines across campus.

Several of the interviewees stated that they have encountered resistance to the Framework. In their experiences, while some librarians, faculty, and administrators have responded positively, even enthusiastically, to the Framework, others have shown resistance. Many faculty, for example, still want a skills-based approach to instruction, even if they find the Framework itself to be conceptually appealing. And some of the interviewees have encountered resistance because the Framework is at such a highly conceptual level. Abby stated,

Part of what we talked about was this criticism of the Framework that it is elitist. That because it's focusing on sort of philosophy more than practical research skills, that it might not be exactly what all students want out of a research class. And so, that is something that I keep in mind now when I try to use the Framework. ${ }^{34}$

\section{RQ4: Evaluation of Student Learning}

Given the difficulties mentioned above, perhaps it is not surprising that several of the interviewees reported that they are not assessing student learning when using the Framework-at least not yet. Others have tried various methods, including assessing student work (produced 
for a course, for instance), surveys of students and faculty, posttests and short quizzes, and formative assessments conducted during sessions. Several of the interviewees admitted that their assessments were still tied to the Information Literacy Competency Standards, which is understandable considering that many of them reported they were still teaching the Standards and using the Framework as a conceptual underpinning in their instruction. As Alexis stated, "...the reason I still use the Standards is the Standards give me concrete things that I can assess on. And the Framework is harder to do, because I think we're trying to detect a change in the being of that learner. And that is impossible to see in a one shot." ${ }^{35}$ Susan reported,

[Assessment] still tends to be skill based but the way we talk about it is more Framework language. So, I might have a worksheet on how you take something from a topic to a research question but I am able to talk about researchers' inquiry in the course of doing that worksheet. For example I am able to use the language of the concepts from that frame in that skill-based activity. ${ }^{36}$

Some of the interviewees said that they are using interviews and self-reflection assignments to gather feedback from students about their experiences with instruction based on the Framework.

Regardless of whether they are or are not (yet) attempting assessment of student learning, the librarians offered opinions about how assessment should be approached. Several noted that there is no single right way to assess, but that multiple options should be explored and that faculty buy-in was essential to developing successful assessment. Some felt that the threshold concepts might not be assessable due to their high level of abstraction. However, they added that it is possible the dispositions associated with each threshold concept, which are phrased as a series of active verbs, could help with developing assessment tools. It was also suggested that assessment, whatever form it takes, needs to be longitudinal so that it can be determined how student learning progresses over time. For Claire, the Framework has caused a shift in the way she conceptualizes assessment:

That's how I would say - I think it's made me become a little bit less obsessive about every single assessment and I'm seeing more of the bigger picture of assessment and the need for collecting little bits of evidence, little pieces over different points in a course, for example. Or, maybe even different points over a student's career that then show the progress of understanding toward these big ideas. Again, you can really see how the Understanding by Design has really possibly influenced me more than the Framework. I don't really - they don't separate now for me anymore. ${ }^{37}$

Alexis explained the complexity of the issues surrounding assessment:

And then the other part is it's hard to change things when you've been working towards the Standards. So, the Standards are behavioral changes that we can see. And the Framework is more impactful, but it's harder to detect, and it's so much more complicated. And I believe that sometimes, for different learners, that change 
is gonna happen at different points in their life. So, they can stay with us in a college environment for the four or five years to get their Bachelor's, and those we've worked with them, but they might not develop into that level of information literacy or critical thinking until much later, even though we're setting up the foundation for them. So, I think it's just hard to assess and hard to discern. ${ }^{38}$

\section{Discussion}

Among the participants who were beginning to implement the Framework, almost all felt that it was having a positive effect on instruction. While most interviewees stated that they were not using the frames explicitly in teaching, they had incorporated the frames as a conceptual underpinning to what they were doing in the classroom. It was interesting to learn that a number of the participants felt the Framework had made their instruction more interactive and more hands-on. For example, rather than using the typical lecture- or demonstration-based approach to teaching, there was more interaction between students and librarians in terms of discussion and questions and answers during instructional sessions. Also, more opportunities were being provided for students to gain hands-on experience in searching for and evaluating different kinds of sources. The Standards, because of their more concrete nature, might have seemed to be the more likely candidate for facilitating interactive and hands-on activities. Instead, the Standards apparently often resulted in lectures and demonstrations instead, perhaps because of their concrete nature. The more abstract frames may actually be encouraging more innovative thinking among these librarians about how to incorporate these high-level concepts into information literacy instruction. In any case, it seems clear that the Framework encourages, one might even say requires, a change in thinking about both instruction and information literacy.

When asked about the most successful strategies for implementing the Framework, the participants spoke of introducing it to other librarians and to faculty across campus, and their attempts to gain buy-in for the reconceptualization of information literacy that the Framework represents. This, too, may relate to the more highly conceptual nature of the Framework and a desire to implement the Framework beyond the limitations imposed by the typical "one-shot" instructional session. At the same time, many of the participants seemed to expect-and reported that they had received - positive feedback about the Framework precisely because it was much more conceptual than the Standards. The emphasis on getting buy-in may also be due to the fact that the participants recognize that a full implementation of the Framework may require more collaboration between librarians and faculty in embedding these concepts into coursework. Having more people on board, especially faculty, could result in students getting instruction in the frames across the curriculum. This finding echoes the advice provided by Troy Swanson, as well as by Kathy Shields and Christine Cugliari. ${ }^{39}$ It also underscores the importance of documenting best practices in developing successful collaborations with faculty and also speaks to the importance of having faculty representation on key library committees as well as librarian representation on key institutional committees.

The participants also noted a number of challenges in trying to implement the Framework. The time limitations of the one-shot instructional approach were a challenge with the Standards and represent even more of a challenge with the Framework. This is also is an area where some differences in the participants' attitudes can be seen. While some clearly felt that the Framework offered a liberating way of thinking about information literacy and instruction 
(reflecting the experience of Rachel Elizabeth Scott, for instance ${ }^{40}$ ), others expressed concern about the concepts being too vague, difficult to teach, and nearly impossible to incorporate into a one-shot session. On a related note, several felt that developing effective instruction using the Framework was much more time consuming than instruction using the Standards. These challenges may be addressed, at least in part, by the growing number of support resources being produced by ACRL and others for implementing the Framework. But this raises an important question: how successful can the Framework be if librarians must seek lots of additional support to incorporate it into their instruction?

Participants also reported different experiences in their librarian and faculty colleagues' reactions to the Framework. Some reported resistance on the part of other librarians and a feeling among faculty that what they wanted was a skills-based approach to information literacy instruction. These feelings stem from a perception that the Framework is too highly conceptual and a conviction that before most students can move onto higher levels of conceptual thinking, they first need to gain basic information literacy skills - skills that are more clearly defined by and easier to measure with the Standards. One participant even reported having heard concerns that the Framework is elitist because it is so conceptual and so abstract, appropriate perhaps for students at a Research I university with highly competitive admissions but far less useful at a community college with an open-admissions policy. As ACRL monitors and assesses the implementation of the Framework, it will be important to keep these issues in mind and ensure that the voices of librarians from different kinds of institutions are heard.

Assessing student learning when implementing the Framework is one of the biggest challenges the participants are facing. The movement away from a skills-based approach to a more conceptual kind of instruction means that librarians are having to rethink how best to evaluate

student learning. It is not surprising that many of them were still assessing skills rather than helping students master one or more of the frames. Generally speaking, most of the participants were not using evaluation based on the Framework, although several of them expressed intentions to try to do so in the future. Future support materials developed by ACRL as well as other parties should focus on how to incorporate meaningful assessment into instruction based on the Framework. Participants indicated that guidance on how to assess student learning using the Framework is a support that they would welcome.

\section{Implications for Research}

The Framework offers fertile ground for future research studies. For example, given that the goals of the Framework are bigger than those of a typical one-shot instructional session, how can the goals of the Framework be achieved in higher education? Also, what is the impact of teaching the Framework - on students' attainment of information literacy, on students' information practices, and on students' overall academic achievement? And what are best practices for preparing both preservice and practicing librarians to teach the Framework? Future studies should include not only the voices of librarians but also those of students and faculty.

Future research can also address how to achieve greater buy-in for the Framework from librarians and faculty as well as the extent to which it is possible to replace the Standards with the Framework. Are there factors that would allow teaching of the Framework to become more explicit, or are the concepts and language truly too difficult for most classroom use? 


\section{Limitations}

The participants in this study represent a small sample of instruction librarians, most of whom are actively working to implement the Framework into their teaching. They were selfselected in that they responded to an email solicitation to participate. Some may have chosen to participate because they had particular experiences with and/or strong feelings about the Framework. Others who responded shared that they had a limited knowledge of the Framework and were still considering how best to incorporate the frames into their instruction. While participants acknowledged challenges in using the Framework, they also represented librarians who are committed to making the transition from the Standards to the Framework. In this sense, there may be a particular bias in the data. Future research should incorporate the point of view of librarians who are more resistant to the changes that the Framework represents. While it is important to remember that the data reported here are not generalizable beyond the group of people who participated in the study, still, as an exploratory study, it provides valuable insight into what is currently occurring in the field and indicates potentially fruitful opportunities for future research studies.

\section{Conclusion}

The introduction of the Framework has generated much excitement as well as some degree of concern. It represents a sea change in the way information literacy (and, by extension, information literacy instruction) is conceptualized. It offers a great deal of flexibility, but not a lot of structure; it is conceptually innovative, but challenging to assess. While respondents say that use of the Framework has made instruction more interactive and conversational, they also report that they are using the frames in an implicit, rather than explicit, manner. It will be important to learn if increased familiarity with the Framework and increased buy-in from colleagues and faculty affect this approach. Future research can track how information literacy instruction evolves over time and how resistance to the Framework among faculty and instructional colleagues can be overcome.

Full implementation of the Framework is difficult given the limitations of the instructional opportunities that most librarians have, such as the one-shot session, and faculty expectations that specific skills will be taught in those sessions. One of the challenges these respondents face is the limitation of time, both in terms of the allowance given them by instructors in the classroom and also in terms of the increased time needed to prepare for class. This is another instance in which buy-in from faculty is critical, but it also points to the need for professional preparation for librarians in using the Framework. Librarians are already finding creative ways to incorporate the frames into instruction; however, examples of new practices that include an assessment of the effectiveness of these approaches would make a useful contribution to the literature on information literacy instruction.

Further, it is difficult to assess student assimilation of the Framework concepts, which may need to be considered over the course of their education. This is perhaps the biggest hurdle to full implementation of the Framework that these respondents report and a topic that they would like assistance with as they need to describe their work to administration and other stakeholders. Research that can demonstrate the effectiveness of the Framework on student attainment of information literacy is critical to the assimilation of this approach in our institutions of higher learning. 
Librarian attitudes toward the Framework vary, so it is important to continue the conversation about the Framework's strengths and weaknesses and how the goals of the Framework can be achieved in higher education. No doubt, there is much to learn, from researchers and practitioners as well as students and faculty, about how the Framework can best be incorporated into instruction at different types of academic institutions. It is also critical to learn what the actual impact of the Framework will be on student attainment of information literacy practices that will serve them outside the academic environment. 


\section{APPENDIX. Interview Guide}

1. How would you describe your institution: community college, 4-year college, university?

2. What's the approximate size of the student body at your institution?

3. How long have you worked as a librarian?

4. What kind of instruction takes place in your library? (one-shot workshop, academic classroom, credit course) and where (library, classroom, computer lab)

5. How did you find out about the Framework for Information Literacy for Higher Education? What got you interested in using it?

6. What steps have you taken to implement the Framework in your information literacy instruction?

a. Look for specific examples

b. If you're not using the Framework, how do you see yourself using it in the future?

7. How has incorporating the Framework affected your instructional practice?

8. Please describe your best success in using the Framework.

9. What do you see as the limitations or difficulties you have encountered in working with the Framework?

10. How have you approached evaluating student learning in your use of the Framework?

11. How have faculty and students responded to the Framework?

a. Are you talking about the frames or using the wording from the frames to talk to faculty and students?

12. To what extent do you see the Framework supplanting an information-skills approach to information literacy instruction?

13. What resources have you used to help with implementing the Framework? (ACRL sandbox, articles, workshops, other)

14. Is there anything else you would like to tell me about the Framework and your experiences with it?

\section{Notes}

1. Framework for Information Literacy for Higher Education, Association of College \& Research Libraries (ACRL) (2016), available online at www.ala.org/acrl/standards/ilframework [accessed 4 April 2018].

2. Ibid.

3. Ibid.

4. Melissa L. Gold and Margaret G. Grotti, “Do Job Advertisements Reflect ACRL's Standards for Proficiencies for Instruction Librarians and Coordinators? A Content Analysis," Journal of Academic Librarianship 39, no. 6 (2013): 558-65.

5. Nicole A. Cooke and Merinda K. Hensley, "The Critical and Continuing Role of Library and Information Science Curriculum in the Teacher Training of Future Librarians," Information Research 18, no. 3 (2013), available online at www.informationr.net/ir/18-3/colis/paperS02.html\#.V3E0evkrJD8 [accessed 4 April 2018]; Yusuke Ishimura and Joan C. Bartlett, "Information Literacy Courses in LIS Schools: Emerging Perspectives for Future Education," Education for Information 27, no. 4 (2010): 197-216; Heidi Julien, "Education for Information Literacy Instruction: A Global Perspective," Journal of Education for Library and Information Science 46, no. 3 (2005): 210-16; Heidi Julien, Maria Tan, and Shannon Merillat, "Instruction for Information Literacy in Canadian Academic Libraries: A Longitudinal Analysis of Aims, Methods, and Success," Canadian Journal of Information and Library Science 37, no. 2 (2013): 81-102; Claudine Sproles, Anna Marie Johnson, and Leslie Farison, "What the Teachers Are Teaching: How MLIS Programs Are Preparing Academic Librarians for Instructional Roles," Journal of Education for Library and Information Science 49, no. 3 (2008): 195-209.

6. Framework for Information Literacy for Higher Education. 
7. Ibid.

8. See Colleen Burgess, "Teaching Students, Not Standards: The New ACRL Information Literacy Framework and Threshold Crossings for Instructors," Partnership: The Canadian Journal of Library and Information Practices and Research 10, no. 1 (2015), available online at https://journal.lib.uoguelph.ca/index.php/perj/article/view/3440\#. Wpl2BOjwZPY [accessed 4 April 2018].

9. See Andrew Battista, Dave Ellenwood, Lue Gregory, Shana Higgins, Jeff Lilburn, Yasmin Sokkar Harker, and Christopher Sweet, "Seeking Social Justice in the ACRL Framework," Communications in Information Literacy 9, no. 2 (2015): 111-25; Lana W. Jackman and Sharon A. Weiner, "The Rescinding of the ACRL 2000 Information Literacy Competency Standards for Higher Education Really??" College \& Undergraduate Libraries 24, no. 1 (2017): $117-19$.

10. Julia Bauder and Catherine Rod, "Crossing Thresholds: Critical Information Literacy Pedagogy and the ACRL Framework," College \& Undergraduate Libraries 23, no. 3 (2016): 252-64.

11. Mahrya Carncross, "Redeveloping a Course with the Framework for Information Literacy for Higher Education: From Skills to Process," CERL News (May 2015): 248-73.

12. Allison Hosier, "Creating Learning Outcomes from Threshold Concepts for Information Literacy Instruction," College \& Undergraduate Libraries 24, no. 1 (2017): 1-13.

13. Trudi Jacobson and Craig Gibson, "First Thoughts on Implementing the Framework for Information Literacy," Communications in Information Literacy 9, no. 2 (2015): 102-10.

14. Rachel Elizabeth Scott, "Accommodating Faculty Requests and Staying True to Your Pedagogical Ideals in the One-shot Information Literacy Session," Communications in Information Literacy 10, no. 2 (2016): 245-63.

15. Zoe Fisher, "Facing the Frames: Using the Framework as a Guide for a Credit-bearing Information Literacy Course," College \& Research Libraries News 78, no. 7 (2017): 354-58.

16. Rachel E. Scott, "Part 1. If We Frame It, They Will Respond: Undergraduate Student Responses to the Framework for Information Literacy for Higher Education," Reference Librarian 58, no. 1 (2017): 1-18; Rachel E. Scott, "Part 2. If We Frame It, They Will Respond: Undergraduate Student Responses to the Framework for Information Literacy for Higher Education," Reference Librarian 58, no. 1 (2017): 19-32.

17. Troy Swanson, "Sharing the ACRL Framework with Faculty," College \& Research Libraries News 78, no. 1 (2017): 12-48.

18. Meredith Farkas, "Framework Freakout? Engaging with the Framework for Information Literacy," American Libraries 48, no. 9/10 (2017): 54.

19. Gloria Willson and Katelyn Angell, "Mapping the Association of College and Research Libraries Information Literacy Framework and Nursing Professional Standards Onto an Assessment Rubric," Journal of the Medical Library Association 105, no. 2 (2017): 150-54.

20. Sonnet Ireland, "For Your Information: Using Information Literacy in Public Libraries," Reference \& User Services Quarterly 57, no. 1 (2017): 12-16.

21. Kathy Shields and Christine Cugliari, "Scholarship as Conversation," College \& Research Libraries News 78, no. 3 (2017): 137-40.

22. Carrie Ludovico, "Seeing the World through Adult Eyes: The ACRL Framework and Continuing Education Students," College \& Research Libraries News 78, no. 5 (2017): 250-54.

23. Amanda Meeks, Larissa Garcia, Ashely Peterson, and Alyssa Vincent, "CREATE: Adapting the Framework to Studio Art Disciplines," College \& Research Libraries News 78, no. 10 (2017): 554-59.

24. Susan Franzen and Colleen Bannon, "Merging Information Literacy and Evidence-based Practice in an Undergraduate Health Sciences Curriculum Map," Communications in Information Literacy 10, no. 2 (2016): 245-63.

25. Heidi Julien, Melissa Gross, and Don Latham, "Survey of Information Literacy Instruction Practices in U.S. Academic Libraries," College \& Research Libraries News 79, no. 2 (2018): 179-99.

26. Elizabeth, interview 1, July 17, 2017. All interviewee names are pseudonyms.

27. Holly, interview 2, July 18, 2017.

28. Claire, interview 11, July 27, 2017.

29. Alexis, interview 13, July 28, 2017.

30. Joanne, interview 4, July 20, 2017.

31. Jill, interview 5, July 20, 2017.

32. Susan, interview 6, July 21, 2017.

33. Holly, interview 2, July 18, 2017.

34. Abby, interview 7, July 24, 2017.

35. Alexis, interview 13, July 28, 2017.

36. Susan, interview 6, July 21, 2017.

37. Claire, interview 11, July 27, 2017. 
38. Alexis, interview 13, July 28, 2017.

39. Swanson, "Sharing the ACRL Framework with Faculty," 12-48; Shields and Cugliari, "Scholarship as Conversation," 137-40.

40. Scott, "Accommodating Faculty Requests," 245-63. 